УДК 070

DOI 10.52575/2712-7451-2021-40-3-316-325

\title{
Кроссмедийная редакция в регионе: принципы организации успешного медиа (на примере МАУ ИД «Мир Белогорья»). Часть 1
}

\author{
Карпенко И.И., Сидорова О.С. \\ Белгородский государственный национальный исследовательский университет, \\ Россия, 308015, г. Белгород, ул. Победы, 85 \\ E-mail: karpenkoirina@bsu.edu.ru
}

\begin{abstract}
Аннотация. Сложный и многогранный процесс конвергенции трансформировал современную журналистику. В практике массмедиа появились кроссмедийные редакции. В соответствии с этим изменились правила создания медиаконтента, способы и принципы распространения материалов СМИ на различных информационных площадках, требования к специалистам, работающим в медиасфере. Наиболее проблемным аспектом в свете анализа кроссмедийной редакционной деятельности является изучение и обобщение опыта региональных средств массовой информации. Цель данного исследования состоит в описании и обобщении практического опыта наиболее успешной редакции Белгородского региона- АНО «Издательский дом «Мир Белогорья». Изучение удачных региональных кроссмедийных практик даст возможность для дальнейшего прикладного применения аккумулированного опыта в работе других региональных медиа. В первой части статьи, посвященной кроссмедийной практике внутриредакционного взаимодействия, представлен анализ специфики создания подобной организации и управления ею, в частности рассмотрены функции генерального директора издательского дома, система оплаты труда кроссмедийной организации, особенности менеджмента в реализации контентной стратегии. Сделан вывод об эффективности кроссмедийного взаимодействия внутри медийной организации.
\end{abstract}

Ключевые слова: кроссмедиа, медиаменеджмент, издательский дом, интернет-СМИ, региональная журналистика, медиахолдинг.

Для цитирования: Карпенко И.И., Сидорова О.С., 2021. Кроссмедийная редакция в регионе: принципы организации успешного медиа (на примере МАУ ИД «Мир Белогорья»). Часть 1. Вопросы журналистики, педагогики и языкознания, 40 (3): 316-325. DOI: $10.52575 / 2712-7451-2021-40-3-316-325$

\section{Crossmedia Editorial in the Region: Principles of the Organization of Successful Media (on the Example of "Mir Belogoria"). Part 1}

\author{
Irina I. Karpenko, Olga S. Sidorova \\ Belgorod National Research University, \\ 85 Pobeda St, Belgorod, 308015, Russia, \\ E-mail: karpenkoirina@bsu.edu.ru
}

\begin{abstract}
The complex and multifaceted process of convergence has transformed modern journalism. Crossmedia editions have appeared in the practice of mass media. In accordance with this, the rules for the development and creation of media content have changed, the methods and principles of distributing media materials on various information platforms, the requirements for various specialists working in the media sphere: chief editors, producing reactors, journalists. The most problematic aspect in the light of the analysis of cross-media editorial practices is the study and generalization of the experience of regional mass media. The purpose of this study is to describe and summarize the practical experience of the most
\end{abstract}


successful editorial staff of the Belgorod region - ANO Publishing House Mir Belogorya. The study of successful regional crossmedia practices will provide an opportunity for further practical application of the accumulated experience in the work of other regional media. The first part of the article, devoted to the crossmedia practice of intra-editorial interaction, presents an analysis of the specifics of creating such an organization and its management, in particular, the functions of the general director of a publishing house, the remuneration system of a crossmedia organization, and management features in the implementation of a content strategy are considered. The conclusion is made about the effectiveness of cross-media interaction within the media organization.

Keywords: crossmedia, media management, publishing house, online media, regional journalism, media holding.

For citation: Karpenko I.I., Sidorova O.S., 2021. Crossmedia Editorial in the Region: Principles of the Organization of Successful Media (on the Example of "Mir Belogoria"). Part 1. Issues in Journalism, Education, Linguistics, 40 (3): 316-325 (in Russian). DOI: 10.52575/2712-7451-2021-40-3-316-325

\section{Введение}

В практике СМИ понятие кроссмедийной редакции возникло в связи с бурным развитием информационных технологий и под влиянием процесса конвергенции. Толчком к развитию феномена кроссмедийности стало появление Интернета и его дальнейшая трансформация в полноценное информационно-коммуникационное пространство, которое в дальнейшем послужило катализатором развития нового явления - интернет-СМИ [Карпенко, 2011, с. 183]. Многие исследователи, говоря об активном внедрении технологий в журналистскую сферу, отмечают роль процесса конвергенции не только в становлении онлайн-медиа, но и в глобальных переменах в структуре и системе СМИ. Появилась так называемая конвергентная или мультимедийная, кроссмедийная журналистика, которая имеет возможность совмещать различные типы контента: текстовую информацию, видео, звук, фото, графику [Симкачева, 2015].

Как отмечает В.В. Волкова, в настоящее время кроссмедийность «объединила традиционно разграничиваемые СМИ в тотальную медиасреду, что приводит к взаимопроникновению форм конструирования и презентации контента» [Volkova, 2017, с. 37]. То есть в связи с объединением разных типов СМИ, в том числе и уже существовавших до появления интернета, появляются новые возможности репрезентации мультимедийного контента.

Н.А. Пащенко называет кроссмедийный характер размещения контента яркой тенденцией современной журналистики, связанной с функционированием в одной структуре сразу нескольких площадок. В частности, она обращает внимание на довольно часто встречающийся случай сочетания работы онлайн и оффлайн-медиа [Пащенко, 2019]. При этом исследователь отмечает, что контент, предоставляемый для различных платформ, должен быть увлекательным и релевантным каналу его трансляции [Пащенко, 2019]. Согласно её наблюдениям, такая тенденция появилась в России более десяти лет назад, когда газета «Комсомольская правда» решила начать активное сотрудничество с видеохостингом Rutube. H.A. Пащенко уверена, что до настоящего времени модель сочетания оффлани онлайн-взаимодействия СМИ является одной из самых успешных: «Подобная модель позволяет при минимальных затратах существенно увеличить объем редакционного контента, открыть новые каналы его распространения, расширить аудиторию издания» [Пащенко, 2019, с. 1].

Несмотря на существующие исследования практики кроссмедийных редакций, необходимо продолжить изучение вопроса в контексте опыта современных успешных редакций, которые смогли не просто сохранить свой юридический статус, но и стать постоянно развивающимися и доходными СМИ. Цель данной работы - описание опыта кросс- 
медийной практики в регионах, где конвергентные процессы проходят с сильным отставанием от федеральной и общемировой практики.

В первой части нашего исследования сделан акцент на принципах организации и управления региональной кроссмедийной редакцией. В последующих частях будет уделяться внимание принципам работы с текстом и трансформации профессиональных компетенций журналиста кроссмедийного СМИ.

\section{Объект и методы исследования}

Объектом исследования выступает белгородская кроссмедийная редакция - издательский дом «Мир Белогорья». Рассмотрены особенности функционирования кроссмедийной редакции и принципы управления коллективом, лежащие в основе успешного конвергентного медиа.

Настоящее исследование проводилось с использованием метода включенного наблюдения с опорой на проведенные авторами статьи экспертные интервью ведущих сотрудников АНО ИД «Мир Белогорья»: бывшего генерального директора холдинга Олега Шевцова, который стоял у истоков создания организации и руководил ею с 2013 года по март 2021 года, и нынешнего главного редактора сетевого издания «БелПресса» Ирины Хорошевской.

\section{Результаты и обсуждение}

\section{Что такое кроссмедийная редакция?}

В настоящее время конвергентная, кроссмедийная редакция стала одной из важных и довольно перспективных моделей развития современных массмедиа, так как включает в себя интеграцию различных медиаформатов. Кроссмедийной называют такую редакцию, в которой рабочий процесс происходит по принципу взаимного обмена информацией [Бурдьё, 2002]. Сотрудники кроссмедийной редакции занимаются созданием, обработкой и распространением контента сразу для всех технологических пластов издательства, то есть делают тексты сразу как для печатных, так и для интернет-версии СМИ. Это позволяет дополнять материалы сайта видеороликами или аудиозаписями. Кросс-медийная редакция работает по принципу взаимного обмена информацией. Создание, обработка и распространение контента происходит сразу для всех технологических платформ, то есть «кроссмедиа подразумевают одну историю, представленную в рамках множества каналов» [Мялковская, 2020, с. 72] или однократное производство контента и многократное его тиражирование на разных медиаплатформах [Баранова, 2010, с. 93].

У каждой отдельной платформы есть свой редактор. При этом в такой редакции могут быть отдельные контент-группы на определённые темы. Важную роль в такой редакции играет проводник СМИ. В разных редакциях его могут называть по-разному: выпускающий редактор, шеф-редактор, главный редактор и т.д. Он, как правило, отвечает за общий выход информации на всех платформах. Такой сотрудник разрешает споры между редакторами отдельных СМИ и участвует в редакционных планёрках по поводу того, на какой именно площадке должен выходить тот или иной медиатекст [Сидорова, 2021, с. 49].

Баранова Е.А. в исследовании «Медиаконвергенция как системообразующий фактор трансформации института СМИ» синонимизирует понятия кроссмедийная и конвергентная журналистика. Кроссмедиа, согласно заключению автора, «предполагает использование более чем одного СМИ - аналогового или цифрового; кроссмедийный контент доставляется на различные устройства, такие как КПК, мобильный телефон, телевизор; суть кроссмедиа в том, что один и тот же контент может распространяться по различным платформам» [Баранова, 2019, с. 55-56]. В другом исследовании Баранова Е.А. использует сходный термин кросс-промоушн, утверждая, что «среди основных примеров взаимодействия газетных редакций с интернет-, ТВ- и радио-ресурсами родственной медиакомпании можно выделить кросс-промоушен; использование материалов, созданных другими СМИ родственной медиакомпании; совместное создание контента» [Баранова, 2011, с. 19]. 


\section{Белгородские кроссмедийные редакциии}

На сегодняшний день в Белгородской области функционируют две кроссмедийные редакции: первая - автономная некоммерческая организация издательский дом «Мир Белогорья», в котором выходят печатные издания «Белгородские известия», «Белгородская правда», «Спортивная смена», «Большая переменка», сетевое издание «Переменка31.ру», молодёжный журнал «ОнОнас», а также сетевое издание «БелПресса»; вторая - городской холдинг «Белгород-медиа», который объединяет телерадиокомпанию «Белый город», газету «Наш Белгород», интернет-портал «Белгородские новости» и интернет-радиостанцию «Белый город».

Отметим, что, изучая особенности функционирования этой кроссмедийной редакции, нельзя не рассмотреть причины её появления на региональном медиарынке. По словам Олега Шевцова, который находился у истоков создания издательского дома «Мир Белогорья», основная причина возникновения такой кроссмедийной редакции - это оптимизация работы белгородских СМИ, финансируемых из регионального бюджета. В 2012 году местные власти увидели три основные проблемы, возникшие в медиасфере региона, связанные с печатными СМИ:

1) пересечение форматов изданий: две основные газеты «Белгородская правда» и «Белгородские известия» практически полностью дублировали друг друга содержательно;

2) достаточно низкая производительность труда: из бюджета оплачивалась работа авторов, которые производили всего лишь один-два текста в месяц, что в разы ниже, чем в коммерческих СМИ;

3) отсутствие представительства региональных органов власти в Интернете, отсутствие своего сетевого СМИ. На тот момент в Сети не было полноценного интернетиздания, которое было бы учреждено региональными властями; существовали лишь онлайн-версии печатных изданий, то есть их полные копии.

Необходимость решения этих проблем обусловила создание единого юридического лица - издательского дома «Мир Белогорья» на базе двух отдельных независимых организаций - АНО «Редакция газеты “Белгородские известия”» и АНО «Редакция газеты “Смена"». «Следующим шагом стало создание единого портала для изданий, входящих в медиахолдинг. Таким сайтом сегодня является belpressa.ru <..>. Фактически сам сайт является $<\ldots>$ самостоятельным СМИ в структуре медиахолдинга - интернет-СМИ» [Карпенко, 2017, с. 154] и выступает агрегатором всех материалов издательского дома, являясь отделом оперативной информации организации.

Через несколько лет к «Миру Белогорья» присоединилась газета «Белгородская правда» и две районные газеты - корочанский «Ясный Ключ» и ивнянская «Родина», которые утратили самостоятельный юридический статус и вошли в состав издательского дома. Сначала прошла реорганизация путём слияния, то есть слились в одно юрлицо два предшественника, а затем шла реорганизация путём присоединения, когда новые организации со всеми активами, сотрудниками и авторскими правами на контент присоединялась к издательскому дому «Мир Белогорья». Этот процесс продолжался с 2013 по 2019 г., то есть с момента создания издательского дома: в конце 2017 г. в структуру издательского дома вошла газета Корочанского района «Ясный ключ», а в 2019 году была присоединена ивнянская газета «Родина».

В самом начале пути организации кроссмедийного холдинга будущий главный редактор лично изучал уже имеющийся российский опыт создания конвергентных медиахолдингов на региональном уровне. Среди городов, которые посетил Олег Шевцов, были Липецк, Тамбов и Воронеж. При организации работы белгородской редакции в основном опирались на воронежский опыт. 


\section{Управление кроссмедийной редакцией}

Говоря о специфике управления новой редакцией, стоит отметить, что руководитель издательского дома отвечает за общую редакционную политику, он является тем самым человеком в кроссмедийной редакции, которого называют проводником СМИ. При этом он ответственен не только за информационную, но и за финансовую и кадровую политику всего издательского дома: «Генеральный директор - это по сути шеф-редактор над всеми редакциями. С одной стороны, он определяет информационную политику, с другой стороны, делегирует большую часть полномочий по её реализации главному редактору соответствующего издания. Второе - это человек, который собирает людей, человеккомандообразователь. Он формирует команду под каждое конкретное СМИ, назначает руководителя и потом уже руководитель приводит людей в свой штат».

Другим важным аспектом в работе главного редактора является финансовая политика организации. Издательский дом должен выполнять финансовый план, зарабатывать деньги путём реализации тиража печатных СМИ, продажи рекламы и реализации спецпроектов: от спецвыпусков газет до издания книг, настольных игр и интернет-проектов для внешних заказчиков. В этой ситуации руководитель должен соблюдать баланс между интересами учредителей, интересами аудитории и интересами своего коллектива: создавать комфортные условия для работы как редакторов, так и журналистов. Единственное диверсификация обязанностей в ИД «Мир Белогорья» состоит в разделении специфики печатной и электронной: направление распространения онлайнового контента входило и входит сейчас в обязанности редактора «БелПрессы».

При создании нового юридического лица АНО «Издательский дом "Мир Белогорья"» главному редактору пришлось также перестроить систему оплаты труда. По словам Олега Шевцова, задачей новой системы оплаты труда состояла в стимулировании работников издательского дома производить больше контента. Если раньше важную роль в формировании заработной платы работников печатных изданий играл стаж работника, то в настоящий момент приоритетным стало качество и количество выполняемой ими работы. «Размер фонда оплаты труда редакции должен соотноситься с достигнутыми финансовыми результатами организации, причем оплата труда должна стимулировать журналистов к повышению качества материалов, а значит и читаемости произведенного контента» [Манжула, 1997, с. 111].

\section{Трансформация системы оплаты труда в кроссмедийной редакции}

Перестройка оплаты труда была произведена таким образом: окладная часть практически у всех одинаковая, к ней добавилась небольшая, символическая надбавка за стаж - около 1-2 тысяч рублей. Остальные надбавки составляют гонорарный фонд. Соответственно, если журналист хочет зарабатывать хорошо и много, он должен много и хорошо работать. Оплата производится за количество контента (знаки в тексте) и за его качество (коэффициенты, повышающие оплату труда в процессе производства издания).

Приведем вариант такой системы оплаты из интервью с Олегом Шевцовым: «Например, 35 копеек стоит знак. Если вы пишете какой-либо репортаж с места события в 10 тысяч знаков и коэффициент один, то получается 3,6 тысячи рублей. Если это текст, который вы будете готовить с риском для жизни, например, писать о преступном мире Белгорода, выходя для этого на работу в ночное время вместе с полицией, то будет другой коэффициент, например, 1,5 или 2. Тогда вы получите за него уже 7,2 тысячи рублей. Если вы сидите в офисе и переписываете пресс-релиз, то будет понижающий коэффициент. Например, 0,3. Вы получите всего лишь в районе тысячи рублей за этот же объём контента».

Таким образом, чем больше денег хочет получить журналист за свою работу, тем с большим количеством СМИ внутри издательского дома ему надо сотрудничать. Но в первую очередь ему следует выполнить задачи того издания, за которым журналист закреплён, а затем уже можно выбирать любое другое СМИ издательского дома и предла- 
гать ему какие-либо темы или даже проекты. «Идея кроссмедиа не отрицает возможности использования одной и той же «истории» на нескольких носителях, как раз наоборот» [Никонович, 2019a, с. 29]. При этом, если сотрудник хочет работать только в своём издании, то никто не заставит его писать в другие журналы или газеты, однако это будет напрямую отражаться на его заработной плате.

Существуют, однако, в этой системе оплаты труда и свои оговорки. Так, текст оплачивается в том издании, где он вышел первый раз, если его взяли, например, сразу два СМИ. В случае, когда в одном из изданий холдинга выпустили укороченный текст, а в другом он вышел в большем объёме, расчёт гонорара за публикацию идёт в пользу журналиста.

Другой важнейшей частью организации рабочего процесса в кроссмедийной редакциии здательского дома «Мир Белогорья», являются планёрки, на которых все журналисты и редакторы обсуждают темы для материалов и наиболее подходящие для их реализации форматы, а также решают, как распределять контент по различным информационным платформам. До марта 2020 года, то есть до введения ограничительных мер в связи с пандемией, редакция проводила до пяти таких планёрок в неделю. В настоящий момент после ослабления ограничений издательский дом проводит планёрки один раз в неделю.

По словам Ирины Хорошевской, несмотря на то, что сейчас планёрок стало меньше, редакторы и журналисты попутно в течение каждой недели решают все необходимые вопросы. Как правило, на самой планёрке творческие работники СМИ обсуждают обязательные темы и мероприятия, которые прописаны в еженедельном медиаплане от правительства Белгородской области, так как редакция выполняет госзадание, а также предлагают изданиям свои темы и решают, какое СМИ хочет взять себе тот или иной текст. Незаменимым и полезным инструментом для распределения тем среди изданий стал «Яндекс. Календарь», которым могут пользоваться как редакторы, так и корреспонденты. Туда вносятся различные темы и предложения. Если какое-либо издание, например, газета «Белгородская правда», уже взяла тот или иной текст, то на этой теме будет отметка «БП» и другие участники получат соответствующие оповещения. Таким образом, когда какая-то тема появляется в «Яндекс. Календаре», она проходит своего рода «аукцион» между изданиями.

Дирекция ИД «Мир Белогорья» активно использует в работе инновационные методики менеджмента организации. Так, во время очных планерок все журналисты стоят, несмотря на то что общий зала оснащен всем необходимым для комфортной работы. Этот приём предложила ввести в редакции Оксана Силантьева, тренер-консультант в медиасфере, антикризисный менеджер и специалист по трансформации редакций. Это было предпринято для сокращения времени планерки и повышения эффективности обсуждения проблем повестки дня.

В настоящий момент в редакции произошли кадровые перестановки, в частности с марта 2021 года и по настоящий момент редакцию возглавляет Олеся Шевцова. Ранее она работала директором спецпроектов ставропольского телеканала «Своё ТВ». В ИД «Мир Белогорья» новый руководитель выполняет в большей степени управленческие функции, тогда как за процесс распределения контента по различным изданиям и проведение планёрок отвечает редактор «БелПрессы» Ирина Хорошевская. Сегодня в редакции проходят активные кадровые перестановки: в первую очередь сокращен штат журналистов. Однако, несмотря на это, принципы работы с текстами и в целом особенности функционирования ИД «Мира Белогорья» как кроссмедийной редакции не изменились.

\section{Заключение}

На примере опыта издательского дома «Мир Белогорья» можно убедиться, насколько успешно удается оптимизировать работу нескольких средств массовой информации, которые ранее существовали отдельно и конкурировали друг с другом (за аудито- 
рию и бюджетные деньги). Если ранее было много «неэффективных» изданий, то сейчас заметно увеличилось производство контента и количество площадок для его распространения. В работе редакции появилась возможность получать не только основную зарплату, но и премии за количество и качество контента. Сегодня издательский дом работает по принципу взаимного обмена: на редакционных планёрках журналисты из всех представленных изданий обсуждают предстоящие мероприятия и важные темы, распределяют задания и стараются сделать так, чтобы в изданиях для схожей аудитории не появлялись одни и те же тексты.

Подобный опыт организации эффективного руководства крупной холдинговой компанией подтверждается многочисленными достижениями редакции: успешными журналистскими проектами, удачной реализацией издательской деятельности и аутсорсинговых проектов и, как следствие, увеличением капитала предприятия и ростом чистой прибыли, о чем свидетельствуют данные из открытых финансовых источников.

Во второй части нашего исследования кроссмедийных практик региональных СМИ мы уделим внимание принципам работы с текстом в конвергентной редакции.

Выражаем признательность сотрудникам АНО «Издательский дом «Мир Белогорья» и лично Олегу Леонидовичу Шевцову, кандидату филологических наук, бывшему генеральному директору издательского дома, за оказанную помощь при сборе материала для публикации. От лица студентов и сотрудников факультета журналистики хотим также поблагодарить Олега Леонидовича за многолетнее плодотворное сотрудничество с НИУ «БелГУ» и за совместную плодотворную работу по подготовке высокопрофессиональных журналистских кадров. Также мы крайне признательны Ирине Юрьевне Хорошевской, главному редактору сетевого издания «БелПресса», за сотрудничество и передачу иенного профессионального опьыта.

\section{Список литературы}

1. Амзин А., Галустян А., Гатов В., Кастельс М., Кульчицкая Д., Лосева Н., Паркс М., Паранько С., Силантьева О., Хаак ван дер Б. 2016. Как новые медиа изменили журналистику. 2012 2016. Под ред. С. Балмаевой, М. Лукиной. Екатеринбург, Гуманитарный университет, 304 с.

2. Баранова Е.А. 2010. Конвергенция СМИ глазами российских журналистов-практиков. Вестник Московского университета. Серия 10. Журналистика, 4: 91-100.

3. Баранова Е.А. 2011. Особенности развития газетных редакций в условиях медиаконвергенции. Автореф. дисс. ... канд. филол. наук. Москва, 25 с.

4. Баранова Е.А. 2019. Медиаконвергенция как системообразующий фактор трансвормации иститута СМИ. Дис. ... докт. филол. наук. Москва, 382 с.

5. Бурдьё П. 2002. О телевидении и журналистике. Пер. с фр. Т. Анисимовой, Ю. Марковой. Под ред. Н. Шматко. М., Институт экспериментальной социологии, 160 с. URL: https://gtmarket.ru/library/articles/3061 (Pierre Bourdieu. 1996. Sur la télévision, suivi de L’Emprise du journalisme. Liber.)

6. Карпенко И.И. 2011. Трансформация профессиональных компетенций журналистов интернет-радиовещания. Научные ведомости Белгородского государственного университета Серия: Гуманитарные науки, 24 (119): 183-187.

7. Карпенко И.И. 2017. Проблема качества интернет-версий печатных СМИ как одно из направлений стратегии создания АНО «Издательский дом “Мир Белогорья”». В кн.: Медиа в современном мире. Петербургские чтения. Материалы 56-го международного научного форума 13-14 апреля 2017 г., Санкт-Петербург. Век информации, 2-2: 153-154. 
8. Качкаева А.Г., Кирия И.В., Коломеец К.Г., Лосева Н.Г., Силантьева О.М., Телень Л.О., Тихомирова Т.Б., Филимонов М.Г. 2010. Журналистика и конвергенция: почему и как традиционные СМИ превращаются в мультимедийные. Под ред. А.Г. Качкаевой. М., 200 с.

9. Манжула В.Г., Манжула Е.В. 2020. Мотивационная модель оплаты труда журналистов сетевого интернет издания. Международный научно-исследовательский журнал, 7-3 (97): 110-114.

10. Мялковская Д.И. 2020. Конвергентная революция. опыт осмысления подходов к кроссмедиа и трансмедиа технологиям. В кн.: Синтез науки и образования в решении глобальных проблем современности. Сборник статей по итогам Международной научно-практической конференции, 24 октября 2020, Саратов. Под ред. А.А. Сукиасяна. Стерлитамак, Агентство международных исследований: 70-78.

11. Никонович Д.О. 2019а. Адаптация газетного контента к размещению на онлайнплатформе. В кн.: Мультимедийная журналистика: медиакоммуникации и медиаиндустрия. Материалы II Международной научно-практической конференции, 1 марта 2019 г., Минск. Под ред. Н.А. Федотовой. Минск, БГУ: 28-31.

12. Никонович Д.О. 2019б. Кроссмедийные тактики в редакции региональной газеты: новая производственная логика. В кн.: Журналістыка-2019: стан, праблемы і перспектывы. Матэрыялы 21-й Міжнар. навук.-практ. канф., 14-15 ліст. 2019 г., Мінск. БДУ: 159-169.

13. Пащенко Н.А. 2019. Кроссмедийное взаимодействие видеоблогов и традиционных телеканалов (на примере пермского трэвел-проекта «Доступный Урал»). В кн.: Ломоносов-2019. Материалы Международного молодежного научного форума, 8-12 апреля 2019 г., Москва. Под ред. И.А. Алешковскиого и др. М., МАКС Пресс: 1-2. URL: https://lomonosovmsu.ru/archive/Lomonosov_2019/data/15705/92347_uid342395_report.pdf (дата обращения: 05.05.2021).

14. Сидорова О.С. 2021. Кроссмедийность как тренд современных медиа. В кн.: Журналистика, массовые коммуникации и медиа: взгляд молодых исследователей. Сборник материалов Научно-практической конференции молодых исследователей, аспирантов и студентов. 8-14 апреля 2021 г., Белгород. Науч. ред. Е.А. Кожемякин и др. Белгород: ООО «Космос»: 47-52.

15. Сидорова О.С., Карпенко И.И. 2018. Профессиональные компетенции современного интернет-журналиста. Современный дискурс-анализ, 3-3 (20). Спец. Выпуск: Дискурс современных массмедиа в перспективе теории, социальной практики и образования. Материалы Международной научно-практической конференции, 3-5 октября 2018 г., Белгород.: 12-21.

16. Симкачева М.В. 2015. Интернет и сетевые технологии в журналистике. В кн.: Информационное поле современной России: практики и эффекты. XII международная научнопрактическая конференция, 15-17 октября 2015 г., Казань. URL: http://kpfu.ru/staff_files/ F1987772493/1_Internet_i_setevye_tehnologii_v_zhurnalistike.pdf (дата обращения: 15.06.2021).

17. Volkova V.V. 2017. Cross-mediality as development factor of the media's visual language. Медиалингвистика. 4 (19): 37-41. URL: https://medialing.ru/cross-mediality-as-development-factor-ofthe-medias-visual-language/ (дата обращения: 09.12.2020) (in English).

\section{References}

1. Amzin A., Galustyan A., Gatov V., Kastel's M., Kul'chitskaya D., Loseva N., Parks M., Paran'ko S., Silant'eva O., Khaak van der B. 2016. Kak novye media izmenili zhurnalistiku. 2012-2016 [As new media changed journalism. 2012-2016]. Eds. S. Balmaeva, M. Lukina. Ekaterinburg, Publ. Gumanitarnyy universitet, $304 \mathrm{p}$.

2. Baranova E.A. 2010. Konvergentsiya SMI glazami rossiyskikh zhurnalistov-praktikov [Media Convergence Through the Eyes of Russian Practicing Journalists]. Vestnik Moskovskogo universiteta. Ser. 10. Zhurnalistika, 4: 91-100.

3. Baranova E.A. 2011. Osobennosti razvitiya gazetnykh redaktsiy v usloviyakh mediakonvergentsii [Features of the Development of Newspaper Editors in the Conditions of Media Convergence]. Abstract diss. ... cand. philol. sciences. Moscow, 25 p.

4. Baranova E.A. 2019. Mediakonvergentsiya kak sistemoobrazuyushchiy faktor transvormatsii istituta SMI [Media convergence as a backbone factor in the transformation of the media institution]. Dis. .... doct. philol. sciences. Moscow, 382 p. 
5. Burd'e P. 2002. O televidenii i zhurnalistike [On television and journalism]. Per. s fr. T. Anisimovoy, Yu. Markovoy. Ed. N. Shmatko. M., Publ. Institut eksperimental'noy sotsiologii, 160 p. URL: https:/gtmarket.ru/library/articles/3061 (Pierre Bourdieu. 1996. Sur la télévision, suivi de L'Emprise du journalisme. Liber.)

6. Karpenko I.I. 2011. Transformatsiya professional'nykh kompetentsiy zhurnalistov internetradioveshchaniya [Transformation of Professional Competencies of Internet Radio Broadcasting Journalists]. Scientific bulletin of Belgorod State University. Humanities Sciences, 24 (119): 183-187.

7. Karpenko I.I. 2017. Problema kachestva internet-versiy pechatnykh SMI kak odno iz napravleniy strategii sozdaniya ANO «Izdatel'skiy dom "Mir Belogor'ya"» [The problem of the quality of online versions of print media as one of the directions of the strategy of creating the ANO "Publishing House "Mir Belogorya"]. In: Media v sovremennom mire. Peterburgskie chteniya [Media in the modern world. Petersburg readings]. Materials of the 56th International Scientific Forum April 13-14, 2017, St. Petersburg. Information Age, 2-2: 153-154.

8. Kachkaeva A.G., Kiriya I.V., Kolomeets K.G., Loseva N.G., Silant'eva O.M., Telen' L.O., Tikhomirova T.B., Filimonov M.G. 2010. Zhurnalistika i konvergentsiya: pochemu i kak traditsionnye SMI prevrashchayutsya $\mathrm{v}$ mul'timediynye [Journalism and Convergence: Why and How Traditional Media Are Transformed into Multimedia]. Ed. A.G. Kachkaeva. M., 200 p.

9. Manzhula V.G., Manzhula E.V. 2020. Motivatsionnaya model' oplaty truda zhurnalistov setevogo internet izdaniya [Motivational model of remuneration for journalists of the online Internet publication]. International Research Journal, 7-3 (97): 110-114.

10. Myalkovskaya D.I. 2020. Konvergentnaya revolyutsiya. opyt osmysleniya podkhodov k krossmedia i transmedia tekhnologiyam [The Convergent Revolution. experience in comprehending approaches to crossmedia and transmedia technologies]. In: Sintez nauki i obrazovaniya v reshenii global'nykh problem sovremennosti [The synthesis of science and education in solving global problems of our time]. Collection of articles on the results of the International Scientific and Practical Conference, October 24, 2020, Saratov. Ed. A.A. Sukiasyan. Sterlitamak, Publ. Agentstvo mezhdunarodnykh issledovaniy: $70-78$.

11. Nikonovich D.O. 2019a. Adaptatsiya gazetnogo kontenta k razmeshcheniyu na onlaynplatforme [Adaptation of Newspaper Content to Placement on an Online Platform]. In: Mul'timediynaya zhurnalistika: mediakommunikatsii i mediaindustriya [Multimedia journalism: media communications and media industry]. Materials of the II International Scientific and Practical Conference, March 1, 2019, Minsk. Ed. N.A. Fedotova. Minsk, Publ. BGU: 28-31.

12. Nikonovich D.O. 2019b. Crossmedia tactics in the editorial office of a regional newspaper: new production logic. In: Zhurnalistyka-2019: stan, prablemy i perspektyvy [Journalism-2019: status, problems and prospects]. Proceedings of the 21st International. scientific-practical conf., 14-15 letters. 2019, Minsk. Resp. ed. V.M. Samusevich. Minsk, Publ. БДУ: 159-169 (in Russian)

13. Pashchenko N.A. 2019. Krossmediynoe vzaimodeystvie videoblogov i traditsionnykh telekanalov (na primere permskogo trevel-proekta «Dostupnyy Ural») [Cross-media interaction of video blogs and traditional TV channels (on the example of the Perm travel project "Accessible Ural")]. In.: Lomonosov-2019 [Lomonosov-2019]. Materials of the International Youth Scientific Forum, April 8-12, 2019, Moscow. Eds. I.A. Aleshkovsky et al. M., Publ. MAKS Press: 1-2. Available at: https://lomonosov-msu.ru/archive/Lomonosov_2019/data/15705/92347_uid342395_report.pdf (accessed: 05.05.2021).

14. Sidorova O.S. 2021. Krossmedijnost' kak trend sovremennyh media. [Cross-media as a trend of modern media]. In: ZHurnalistika, massovye kommunikacii i media: vzglyad molodyh issledovatelej. [Journalism, Mass Communications and Media: the view of young researchers]. Collection of materials of the Scientific and practical conference of young researchers, postgraduates and students. April 8-14, 2021, Belgorod. Scientific ed. E. A. Kozhemyakin et al. Belgorod, OOO "Kosmos": 47-52.

15. Sidorova O.S., Karpenko I.I. 2018. The professional competences of a modern online journalist. In: Sovremennyy diskurs-analiz, 3-3 (20). Special Issue: Diskurs sovremennykh massmedia v perspektive teorii, sotsial'noy praktiki i obrazovaniya [Discourse of modern mass media in the perspective of theory, social practice and education]. Materials of the International Scientific and Practical Conference, October 3-5, 2018. Belgorod: 12-21.

16. Simkacheva M.V. 2015. Internet $\mathrm{i}$ setevye tekhnologii $\mathrm{v}$ zhurnalistike [Internet and Networking Technologies in Journalism]. In: Informatsionnoe pole sovremennoy Rossii: praktiki i effekty [Information field of modern Russia: practices and effects]. XII International Scientific and Practical 
Conference, October 15-17, 2015, Kazan. Available at: http://kpfu.ru/staff_files/ F1987772493/1_Internet_i_setevye_tehnologii_v_zhurnalistike.pdf (accessed: 15.06.2021).

17. Volkova V.V. 2017. Cross-mediality as development factor of the media's visual language. Media Linguistics. 4 (19): 37-41. Available at: https://medialing.ru/cross-mediality-as-developmentfactor-of-the-medias-visual-language/ (accessed: 09.12.2020) (in English).

Конфликт интересов: о потенциальном конфликте интересов не сообщалось.

Conflict of interest: no potential conflict of interest related to this article was reported.

\section{ИНФОРМАЦИЯ ОБ АВТОРАХ}

Карпенко Ирина Ивановна, кандидат филологических наук, доцент кафедры журналистики Института общественных наук и массовых коммуникаций Белгородского государственного национального исследовательского университета, г. Бедгород, Россия

Сидорова Ольга Сергеевна, корреспондент сетевого издания Fonar.tv, ООО «МасМедиа», г. Белгород, Россия

\section{INFORMATION ABOUT THE AUTHORS}

Irina I. Karpenko, Candidate of Philology, Associate Professor of the Department of Journalism, Institute of Social Sciences and Mass Communications, Belgorod National Research University, Bedgorod, Russia

Olga S. Sidorova, correspondent for the network publication Fonar.tv, MasMedia LLC, Belgorod, Russia 